\title{
Behavioral differentiation of septal lesions in two strains of rats
}

\author{
D. A. BARTSCH and L. J. ENLOE \\ Idaho State University, Pocatello, Idaho 83201
}

\begin{abstract}
Wistar albino rats and Long-Evans hooded rats were subjected to lesions of the septum or to control procedures, and then were tested for emotional reactivity and acquisition of shuttle avoidance, one-way avoidance, or passive avoidance tasks. While septal lesioned animals differed from controls on all measures, there was a strain difference between lesioned Wistar and lesioned Long-Evans rats only on tests of emotionality and one-way avoidance. There were no strain differences observed on shuttle or passive avoidance tasks. Additionally, there were no statistical differences between albino controls and hooded controls on any measure, although albino animals did score consistently lower in emotionality.
\end{abstract}

Septal lesions have been shown to result in a variety of effects, dependent on the species being tested. For example, the "septal rage" syndrome noted by Brady and Nauta (1953) occurs only in rodents, and not in hamsters (Sodetz \& Bunnell, 1970), guinea pigs (Levinson, Reeves, \& Buchannan, Note 1) cats (Moore, 1964), or monkeys (Buddington, King, \& Roberts, 1967). In contrast, rats (King, 1958), cats (McCleary, 1961), and monkeys (Buddington et al., 1967) exhibit enhanced two-way avoidance following septal lesons; and both cats (McCleary, 1961) and rats (Kaada, Rasmussen, \& Kveim, 1962) with septal lesions display a large impairment on passive avoidance tasks. Finally, lesioned rats exhibit retarded acquisition of a one-way avoidance task (Kenyon \& Krieckhaus, 1965; Vanderwolf, 1964), whereas cats do not (Zucker, 1965).

There is recent evidence that the effects of septal lesions also differ between strains of the same species. Oliverio, Castellaro, and Messeri (1973) report significant lesion and strain interactions for inbred mice tested for activity, shuttle avoidance, and discriminated avoidance learning. Similarly, Deagle and Lubar (1971) have reported that septal lesions have different effects on the avoidance learning of LongEvans and Sprague-Dawley rats. Although these authors found that the two strains did not differ with respect to the effects of septal lesions on shuttle avoidance acquisition, they did find that lesioned Long-Evans rats failed to show retarded acquisition of a one-way task, whereas lesioned Sprague-Dawley rats were significantly retarded in acquiring the task.

One interpretation of these findings might be that septal lesions act to amplify the genetic differences which are already present in the subjects being studied (Thomas, Hostetter, \& Barker, 1968). Strains of rats have been shown to vary significantly with respect to emotionality (Stone, 1932; Freudenberger,
1932) and avoidance behavior (Nakamura \& Anderson, 1962), and it is possible to manipulate trials to avoidance criterion by selective breeding in both rats (Bignami, 1965) and mice (Oliverio, 1971). On the other hand, little is known as to how these effects interact with the effects of septal damage. Thus, the current study was designed to delineate the extent of Lesion by Strain by Task interactions with respect to three measures of avoidance learning: shuttle avoidance, one-way avoidance, and passive avoidance. Additionally, the comparisons were extended to include measurement of emotional reactivity. This manipulation was performed with the expectation that intraspecific comparisons might help to illuminate the nature of the lesion-induced deficits on avoidance learning. In particular, the contribution of emotionality to avoidance leaning was accessed by utilizing statistical control techniques.

\section{METHOD}

\section{Subjects}

The subjects were 36 male Long-Evans hooded rats and 36 male Wistar albino rats. As supplier differences are known to affect avoidance scores, both strains of rats were obtained from the same supplier, Charles-River Breeding Laboratory. On receipt, the rats were assigned to groups as follows: 18 Long-Evans rats were given septal lesions (Group HS), 18 Wistar albino rats were given septal lesions (Group AS), and 18 of each strain underwent control procedures (Groups AC and $\mathrm{HC}$ ). Each group was further subdivided into one of three avoidance tasks: one-way avoidance, shuttle avoidance, and passive avoidance, such that six animals from each group were trained on each task. Assignments were random, except as needed to fill all groups. All subjects were individually housed in suspended Wahmen cages, and were maintained on ad-lib feed and water, except during the deprivation period associated with passive avoidance training and testing.

\section{Apparatus}

The one-way avoidance apparatus consisted of a $10 \times 11 \times$ $125 \mathrm{~cm}$ gray wooden runway. The last $29 \mathrm{~cm}$ on one end was painted black and served as the goalbox. The startbox was located 
at the opposite end, and consisted of a $10 \times 11 \times 29 \mathrm{~cm}$ gray wooden box mounted directly over the runway. The floor of the startbox was a trap door that was electrically wired so that when the door opened a CS (buzzer) was initiated. Illumination was provided by a $15-\mathrm{W}$ bulb centered $90 \mathrm{~cm}$ above each end of the runway. The floor of the runway consisted of grids, while the floor of the goalbox was of wood and the cover of Plexiglas.

The apparatus for the two-way active avoidance conditioning consisted of a $17 \times 18 \times 40 \mathrm{~cm}$ shuttlebox. The floor was formed by $1 / 4$-in. stainless steel bars spaced $3 / 4$-in. apart. One half of the inside of the box was painted white and the other half painted black. The grids in each of the colored compartments were independently electrified. Illumination was provided by a $71 / 2-W$ bulb centered $90 \mathrm{~cm}$ above the box.

The apparatus for the passive avoidance was modeled after the box used by Ursin, Linck, and McCleary (1969). It consisted of a gray $10 \times 25 \times 25 \mathrm{~cm}$ startbox that opened into two alleys extending in opposite directions. Both alleys were of equal dimensions $(10 \times 11 \times 75 \mathrm{~cm})$, and each terminated in a $10 \times$ $25 \times 25 \mathrm{~cm}$ goalbox. One alley and its goalbox was painted white, and the other alley and goalbox was painted black. The floor of the Ursin box was marked off into nine sections of equal length. A $15-\mathrm{W}$ bulb was suspended centrally $75 \mathrm{~cm}$ above the startbox. The floors of the goalboxes consisted of metal plates, and the food containers were plastic dishes containing wet mash. The floors and walls of the alleyways were wood and the apparatus was covered with Plexiglas. A $10 \times$ $11 \times 20 \mathrm{~cm}$ removable enclosure was used within the startbox to restrain the individual rats.

\section{Surgical Procedure}

All animals received the appropriate surgical treatment when they reached a weight of 280 to $350 \mathrm{~g}$. Groups AS and HS sustained septal lesions, and Groups $\mathrm{AC}$ and $\mathrm{HC}$ underwent a surgical control procedure which consisted of a midline incision and removal of a section of the cranium by means of a trephine. The surgery was carried out while the rats were treated with a combination of methoxyflurane and sodium pentobarbitol anaesthetics. The rats were also given an injection of atropine to inhibit parasympathetic mucosal secretions during surgery. The bilateral (radio frequency) lesions were accomplished with a unipolar anode electrode, insulated except for $.5 \mathrm{~mm}$ at the tip. A cathode anal plug served to complete the circuit, which used a current of approximately $1 \mathrm{~mA}$ for $20 \mathrm{sec}$. The coordinate values for septal lesions were computed with reference to the DeGroot (1959) atlas and were: AP + 7.8, $\mathrm{L} \pm .5$, and DV + 1.0.

\section{Postoperative Procedures}

Following a 2-day postoperative recovery period, all subjects were individually rated for emotionality, using the procedures and scale described by King (1958). Each rat was tested for 8 consecutive days, and the mean rating of two trained observers became the daily emotionality score for each subject. A correlation coefficient computed for the scores of the two observers was +.99 , indicating a high level of agreement between observers. On the day following completion of the emotionality rating, all subjects began training on the appropriate avoidance tasks, using the procedures given below.

\section{One-Way Avoidance}

One-way training commenced with habituation of the animal to the apparatus and CS (buzzer). For the first $10 \mathrm{~min}$ of habituation, the rat was placed in the runway and allowed to move about in the apparatus. The animal was then placed in the startbox, facing towards the goal box. Thirty seconds later, the trap door was dropped, and the CS, a buzzer, came on. After $5 \mathrm{sec}$, the buzzer was terminated and the rat was given 2 min to explore the apparatus. Three such trials were given on each of 2 consecutive days; then avoidance training was begun.
The avoidance training procedure was identical to that used in the habituation trials, except that the 5-sec CS was followed by a grid shock of approximately $4 \mathrm{~mA}$, measured with the rat in the circuit. Buzzer and shock continued until the animal moved into the goalbox. Each animal was given 20 trials/day until an avoidance criterion of 9 out of 10 successive avoidance responses within a single session was reached. If an animal did not meet criterion by the 100th trial, training was terminated and the animal was given a score of 100 trials to criterion.

\section{Shuttle Avoidance}

The shuttle avoidance task was similar to that used by Van Hoesen, MacDougall, and Mitchell (1969). The first day served to habituate the animal to the apparatus and the CS (buzzer). The animal was placed in the shuttlebox for $15 \mathrm{~min}$, during which random presentations of the 10 -sec CS were made. On the 2nd day, active avoidance training began, using a standard 30-sec intertrial interval (ITI). On all trials, the CS was presented for $10 \mathrm{sec}$ followed by the shock (US), which measured $.4 \mathrm{~mA}$, with the rat in the circuit. If the subject crossed to the opposite side of the box before the US onset, an avoidance response was recorded; otherwise, an escape response was recorded. In either case, the CS was immediately terminated after the rat escaped or avoided, and the clock that timed the 30-sec ITI was reset. Intertrial responses were also recorded but were not punished. A criterion of 22 out of 25 avoidance responses across daily sessions of 25 trials was required. If the subjects failed to reach criterion in 200 trials, no additional testing was given, and the animals were given a score of 200 trials to criterion.

\section{Passive Avoidance}

The procedure used in this experiment was patterned after that used by Ursin et al., (1969). The subjects were maintained on a 23-h food-deprivation schedule throughout training and testing. Free access to standard lab chow was allowed for $45 \mathrm{~min}$ following each daily testing session. For half of the animals in each of the four groups, the white alley and goalbox were reinforced, while the black alley and goalbox were reinforced for the other half. Prior to training, on each of 3 consecutive days, the subjects were given 15 min daily adaptation to the apparatus. A wet mash of ground lab chow and water was available in the appropriate goalbox. Each subject always found the mash in the same goal throughout training and testing. Avoidance training began on the day following the 3-day adaptation period. Five trials were given on the first 2 days and 10 trials were given on the following days of training, until each subject reached criterion. Criterion was 9 out of 10 correct responses on each of 2 consecutive days, or 10 correct on a single day, whichever occurred first.

A trial was initiated by removing the restraining enclosure from the startbox after the 30-sec ITI, thus freeing the subject to enter either the black or the white alley, one of which contained the wet mash reinforcement. A response was scored as correct if the subject first entered the correct alley with all four feet. If the wrong alley was entered first, the trial was scored as incorrect, even though the subject was allowed to correct the response. Under either circumstance, the subjects were allowed 2 min to find the wet mash before the trial was terminated. If they found the mash in the time allotted, they were given time to eat. If the allotted time interval ended before they found the mash, then they were replaced into the startbox and a new trial was initiated. After the 5th day of training, an incorrect choice was punished by confining the subject in the incorrect alley for $30 \mathrm{sec}$ before allowing it to correct itself to obtain the food reward. Once initiated for any given subject, this shaping procedure for incorrect responses was maintained until criterion was reached.

Avoidance testing was done on the 2 nd day after criterion was reached by a given subject. The interim day served as over- 
training, with 10 trials being given in the usual fashion. On the test day, the first 4 trials were run using procedures identical to those used on the preceding days. Beginning with the 5th trial, the subjects were shocked on 2 successive trials when eating the wet mash. To increase the possibility that the subjects would eat voluntarily on the second shock trial, two shock intensities were used, as in Ursin et al. (1969). A .75-mA shock was used on the first shock trial, and a 1.4-mA shock was used on the second. To assure that the subject received the second shock, the incorrect alley was blocked off and, if necessary, the subject was maneuvered into the desired goalbox, where, upon eating, it received the second shock.

After receiving the second shock, the final trial was initiated. When the restraining enclosure was removed, both alleys were open with no food available in either end. The animal's position in the alley segments was then recorded at 10 -sec intervals for a 2-min time period. The segments were numbered in ascending order, beginning with the goalbox in which the subject received reinforcement and was subsequently punished. In those cases where the subject was positioned midway between two segments or in transit from one segment to the next, a score intermediate to the two segments was recorded. The final score given each subject was a mean of the scores for each 10 -sec interval during the 2-min test period.

\section{Histological Procedure}

Upon completion of postoperative training and testing, the rats were deeply anaesthetized with sodium pentobarbitol and perfused intracardially with $0.9 \%$ saline, followed by $10 \%$ Formalin. Their brains were then removed, partially frozen, and sectioned at $40 \mu$. Every fifth section was saved and, subsequently, mounted on a slide, stained with thionine, and examined for location and extent of lesion. One lesion is presented in Figure 1 to demonstrate the extent of the typical lesion incurred by the septally lesioned animals. The lesions were found to include the lateral septum, medial septum, paraolfactory area, diagonal band of Broca, stria terminalis, triangular septum, the fornix, and the anterior commissure. The lesion also included to a minimal extent the corpus callosum in the anterior sections, the area of the nucleus accumbens septi and the preoptic area. An evaluation of the extent of the lesions indicated that the size of the lesions was not correlated with the performance of the animals on the respective tasks.

\section{RESULTS}

The results of the tests of emotional reactivity, one-way avoidance, shuttle avoidance, and passive

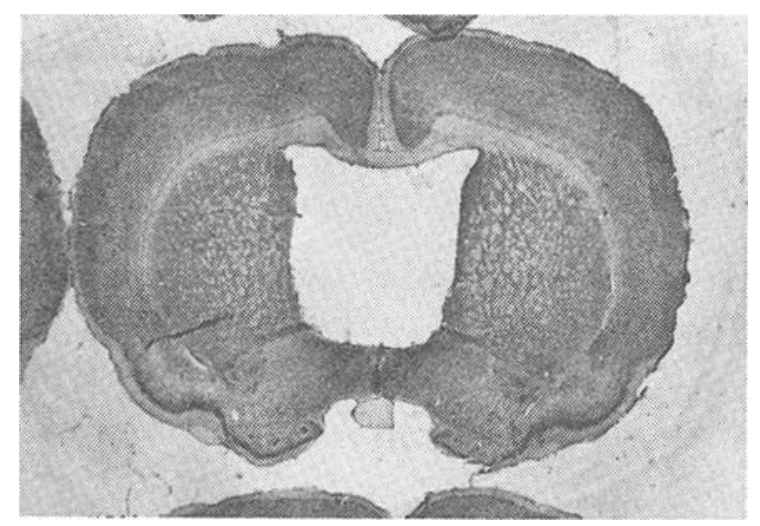

Figure 1. Photomicrograph of typical septal lesion. avoidance were analyzed by separate analyses of variance. Planned comparisions were also carried out to test for differences among treatment groups, and specifically for differences between Long-Evans hooded rats with lesions of the septum (HS) and Wistar albino control rats with septal lesions (AS), lesioned and control groups, and Long-Evans hooded control rats (HC) and Wistar albino control rats (AC). Planned comparisons were performed following the method outlined in Hays (1973). All differences reported as significant, whether from analysis of variance or planned comparisons, were beyond the .01 level of significance.

\section{Emotionality}

The results of the emotional reactivity measure for groups over days are represented graphically in Figure 2. As expected, lesion-induced hyperreactivity was plainly evidenced by both Group AS and Group HS. Both groups exhibited a sustained elevation of emotionality, resulting in a significant lesion effect $[F(3,68)=14.37, p<.01]$. On Day 1 , these subjects had mean scores of 9.93 for Group HC and 8.86 for Group AC. Over time, all groups declined in reactivity to the point where the means for all groups were around 5.5. This decline in emotional reactivity over time was reflected in a significant days effect $[\mathrm{F}(7,476)=129.49, \mathrm{p}<.01]$.

Also indicated by the graph of emotionality, is the differential rate of decline for the groups over days. Groups HC and AC appear to level off around Days 4 to 5 , while the lesioned groups do not reach a level comparable to the control groups until about Day 6 . These differential rates in decline of reactivity over days are reflected in a significant Group by Days interaction $[F(21,476)=10.16, p<.01]$.

Planned comparisons of treatment means show that the difference between lesioned and control groups was significant $[\mathrm{F}(1,572)=94.76, \mathrm{p}<.01]$. There was, moreover, a significant difference between Groups HS and AS, with Group HS being significantly more reactive than Group AS $[F(1,572)$ $=13.24, \mathrm{p}<.01]$. The control group difference was found to be insignificant $[F(1,572)=2.28]$. Thus, the difference between the lesioned and control groups was very dramatic, with the two lesioned groups differing significantly from the control groups and from each other.

\section{One-way Avoidance}

The one-way avoidance results were first assessed by computing trials to criterion for each of the groups. The results of this analysis indicated that the lesioned groups took significantly longer to reach the criterion of 9 out of 10 avoidance responses than did the control groups $[F(1,20)=34.58, p<.01]$. The mean scores for the groups showed that the control groups each averaged less than 15 trials to meet 


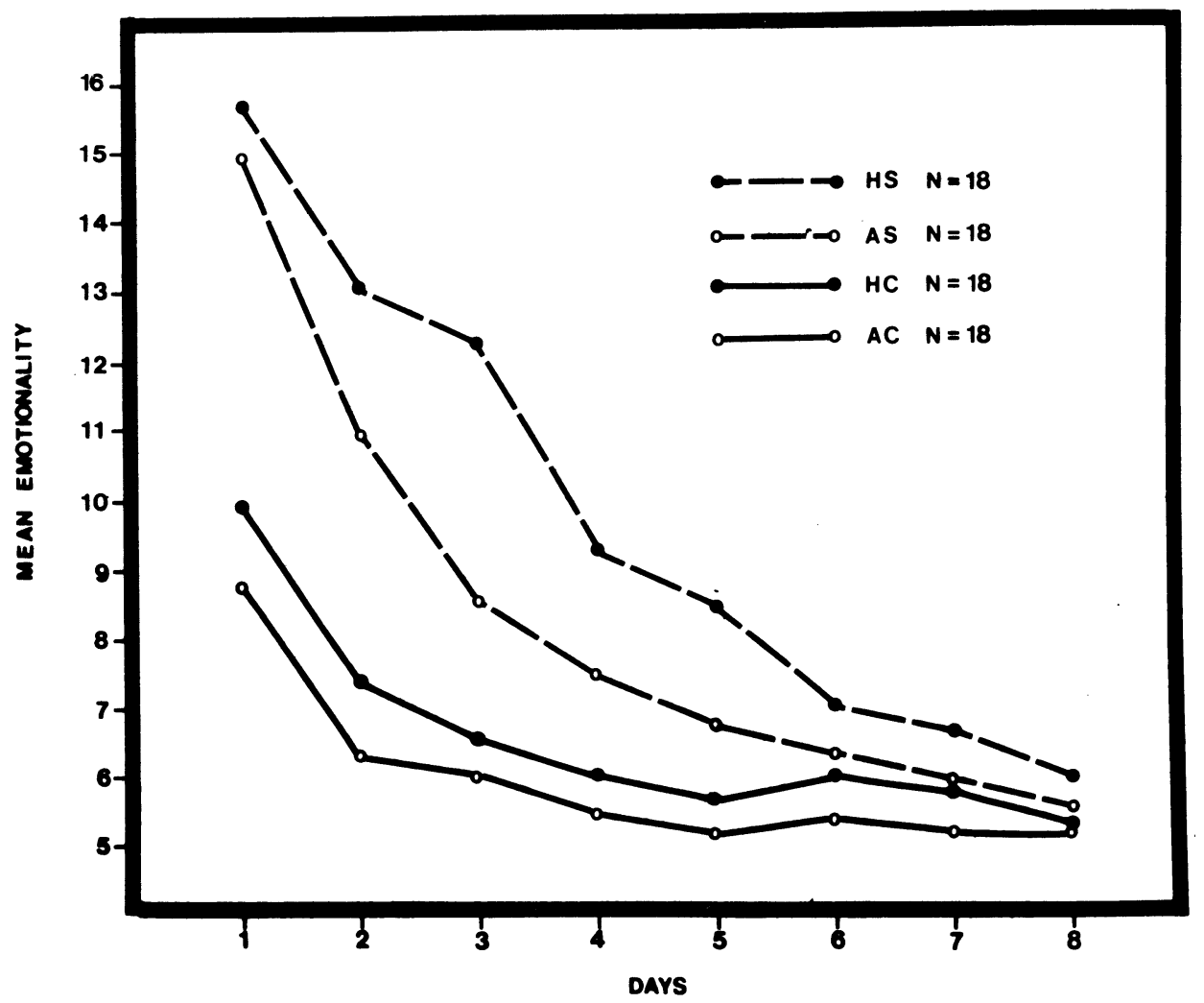

Figure 2. Mean emotionality over days.

the acquisition criterion, whereas Group HS averaged 36.5 trials and Group AS averaged 30.2 trials. While the trend was for the HS subjects to take longer to acquire the response, the test for strain difference did not reach statistical significance $[F(1,20)=1.07]$.

During acquisition of the avoidance response, the groups exhibited a difference with respect to the number of trials elapsed before any avoidance responses were made. For that reason, the results of the one-way paradigm were plotted in the form of a Horel Plot, shown in Figure 3. This figure represents mean trials to reach successive criteria for each group. As such, the figure shows how many trials were made before avoidance responding began. As is clearly indicated, there is a marked differentiation between groups $[\mathrm{F}(3,20)=11.95, \mathrm{p}<.01]$, with the control groups requiring fewer trials to begin making avoidance responses. Both control groups averaged about 6 trials to make their first avoidance responses, while Groups AS and HS required 13.3 and 22.3 trials, respectively. the increase in trials required to meet the successive criteria is reflected in the significant effect due to successive criteria $[F(7,140)$ $=16.63, \mathrm{p}<.01]$.

Despite the differences between groups in total trials to criterion, the Group by Successive Criterion interaction effect was nonsignificant $[F(21,140)=$ 2.29]. This shows that the lines, or slopes of the lines, for the groups are basically equivalent, or parallel. Therefore, once the respective groups began making avoidance responses, they proceeded to reach the criterion of 9 out of 10 at approximately the same

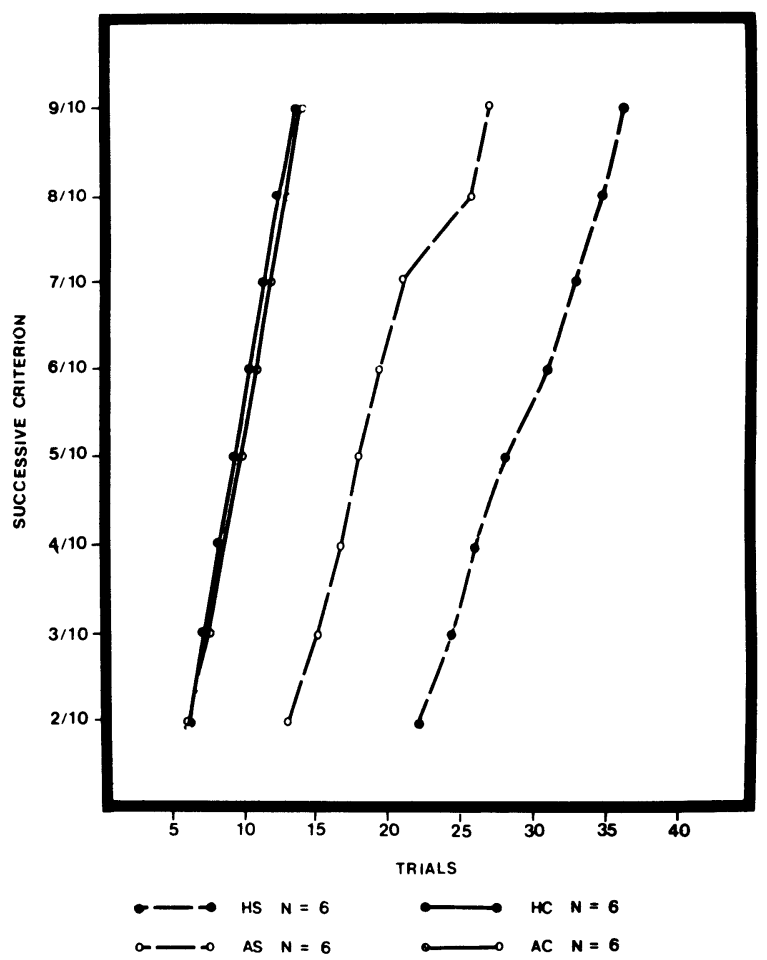

Figure 3. Trials to successive criterion on one-way avoidance. 
rate. Thus the primary difference is in the number of trials until avoidance begins, rather than any difference in rate of learning.

Planned comparisons were utilized to pinpoint the differences among treatment groups, and showed that there was a significant difference between the septal groups and control groups $[\mathrm{F}(1,188)=181.18$, $\mathrm{p}<.01]$. The difference between Groups HS and AS was also significant $[F(1,188)=42.62, p<.01]$, but differences in Groups $\mathrm{HC}$ and $\mathrm{AC}$ did not reach significance $[F(1,188)=.05]$. Thus, there was a significant difference not only between lesioned animals and control animals, but also between the lesioned Long-Evans group and the lesioned Wistar group.

\section{Shuttle Avoidance}

Shuttle avoidance was first assessed by computation of trials to criterion. The septal operated animals met the avoidance criterion of 22 out of 25 avoidance responses in significantly fewer trials than did the nonoperated groups $[\mathrm{F}(1,20)=89.77, \mathrm{p}<.01]$. Groups HS and AS +nok 63.8 and 82.5 trials, respectively, to acquire the aviodance response, while only two of the $\mathrm{HC}$ subjects and no AC subjects reached criterion before the 200 trial termination point. The differences due to strain appear to be large, with the septal groups differing from each other and the control groups. But, as the results of the analysis of variance showed, the strain test was not statistically significant $[\mathrm{F}(1,20)=3.15]$. Also, the interaction effect was found to be nonsignificant $[\mathrm{F}(1,20)=1.76]$.

Figure 4 represents a Horel plot of trials to successive criterion. This figure also indicates a significant effect due to lesions $[\mathrm{F}(3,20)=3.37$, $\mathrm{p}<.05]$. As indicated in the figure, this is due to the fact that Groups AS and HS took less than 20 trials to begin avoidance responding, while Groups AC and $\mathrm{HC}$ took 66 and 83.5 trials, respectively. Also, the groups did not learn at the same rate, as evidenced by the significant Groups by Successive Criterion effect $[F(21,140)=6.1, p<.01]$. And, as indicated by the repeated measures analysis of variance performed on the data represented by the figure, the successive criterion effect was also significant $[\mathrm{F}(7,140)=28.54, \mathrm{p}<.01]$. This was to be expected, however, as the rats required more trials to reach the final criterion of 22 out of 25 avoidance responses.

Planned comparisons carried out on the treatment groups showed a significant difference between septal groups, with the septal groups responding by learning the avoidance response in significantly fewer trials than did the control groups $[\mathrm{F}(1,188)=229.49$, $\mathrm{p}<.01]$. There were no differences in conditioning

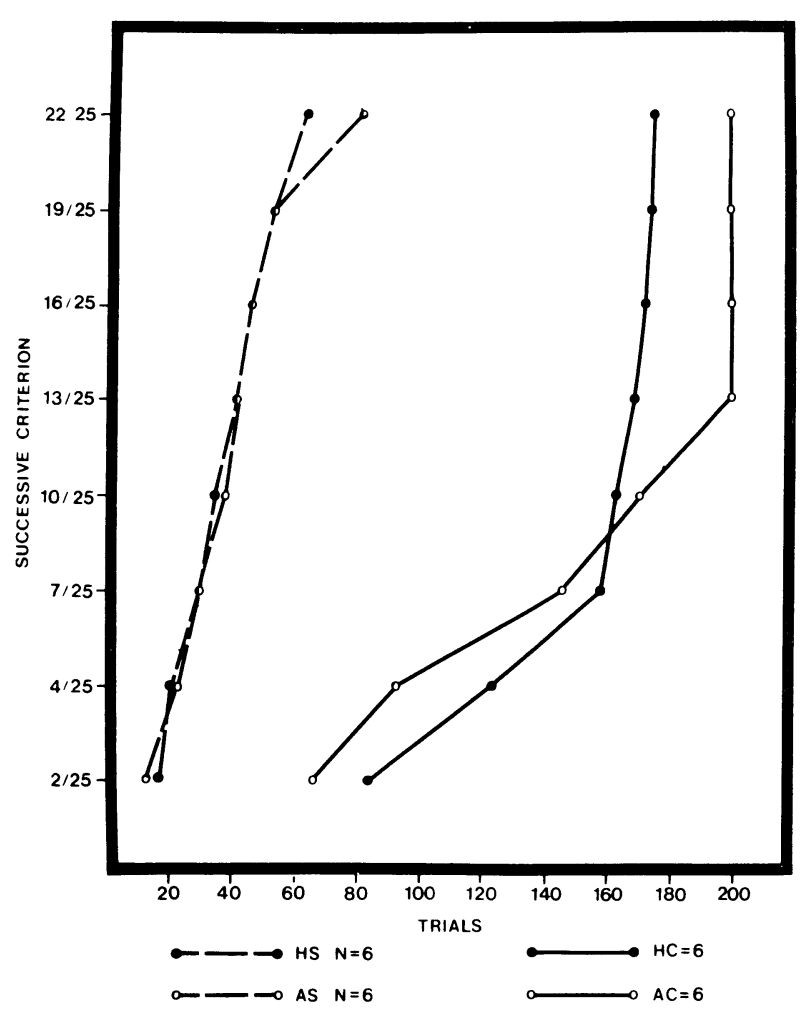

Figure 4. Trials to successive criterion on shuttle avoidance.

due to strain effects, however, since the comparisons between Groups HS and AS and AC and HC were both nonsignificant $[F(1,188)=.04$ and $F(1,188)=$ .4 , respectively].

\section{Passive Avoidance}

The individual scores by groups for the passive avoidance results are represented in Figure 5. As in Ursin, Linck, and McCleary (1969), each bar represents the mean alley position for the 2-min observation period, following the two shock trials. The lines represent the mean alley position for the respective groups. As shown in the figure, the lesioned group with a mean alley position of around 3.3 and the control group with a mean alley position of about 6.5 differed significantly in their avoidance of the box where they were fed and subsequently shocked $[F(1,20)=50.38, p<.01]$. The septal groups showed a passive-avoidance deficit by tending to approach the place where they were shocked, while the control groups either passively avoided by remaining stationary in the startbox or actively moving away from the source of punishment. There was no difference due to strains $[F(1,20)=.63]$. The interaction effect between lesions and strains was also nonsignificant $[\mathrm{F}(1,20)=.03]$.

As expected, planned comparisons computed for differences between treatment means showed a sig- 


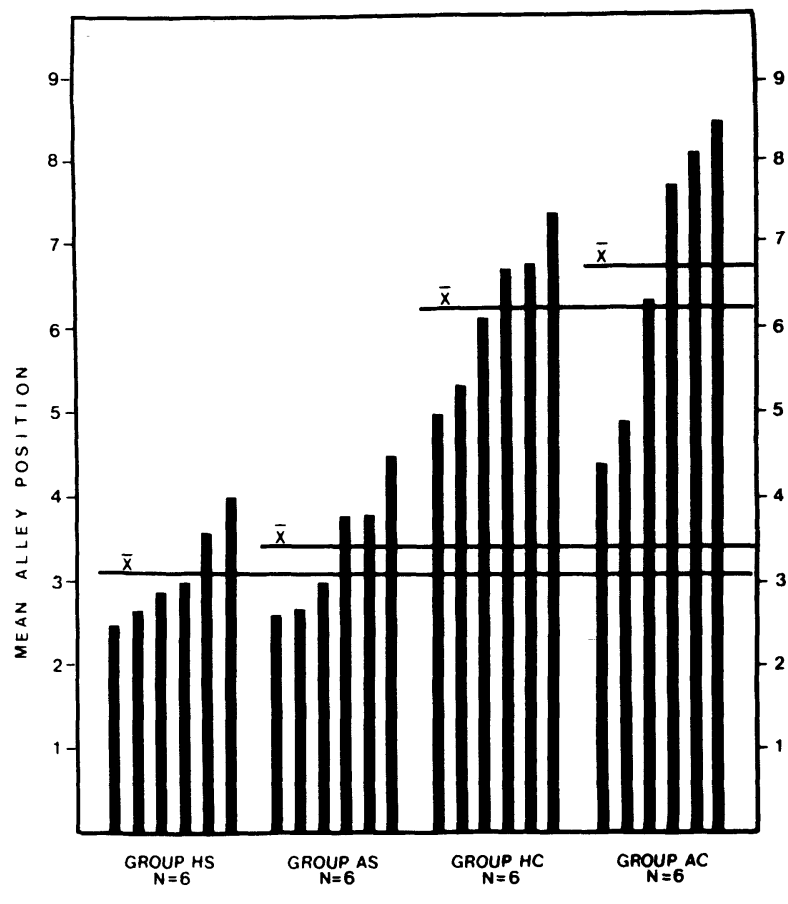

Figure 5. Mean distance from the goalbox during passiveavoidance testing.

nificant difference between lesioned and control groups $[F(1,20)=201.69, p<.01]$. The effect of strains, however, appeared to be negligible for both the HS-AS comparison $[\mathrm{F}(1,20)=.79]$ and the HC-AC comparison $[\mathrm{F}(1,20)=1.87]$.

\section{Covariance}

Taken together, these results indicate that there is a Strain by Lesion interaction only on measures of emotionality and one-way avoidance. On both measures, Group HS scored higher than did Group AS, and both were higher than were the controls of either strain. As these results might indicate commonality of effect (both tasks involved handling, whereas neither of the other tasks did), an analysis of covariance was used as a post hoc statistical control for the variable of emotionality in one-way avoidance. The test results showed that variations in emotionality did not account for variation in trials to criterion $[\mathrm{F}(3,19)=4.65, \mathrm{p}<.025]$.

\section{DISCUSSION}

Lesion, strain, and avoidance test interactions plainly do exist, as evidenced by the results of this experiment. While there were no differences between strains in the control groups on any measure, there were marked differences with respect to lesion effects on Wistar and Long-Evans subjects tested for emotionality and acquisition of a one-way avoidance paradigm. The lesioned Long-Evans group scored higher than the lesioned Wistar group on the emotional reactivity measure, and also in trials to avoidance on the one-way task. In contrast, no difference was found on shuttle avoidance or passive avoidance, although the present study did replicate the well-established septal-lesion effects on these tasks.

These results represent a basic replication of Deagle and Lubar (1971), in that no strain differences were found for shuttle avoidance, whereas there was a significant Lesion by Strain interaction on one-way avoidance. On the one-way task, Wistar rats, like Sprague-Dawley rats, showed a marked deficit in trials to avoidance. However, in the current study, Long-Evans rats showed an even greater deficit both in terms of trials to criterion, and trials to first avoidance response, although only the latter measure was statistically significant. This result differs dramatically from the findings of Deagle and Lubar (1971), in that they reported that Long-Evans rats showed no deficit on the one-way task. One explanation for this discrepancy might be that Deagle and Lubar used a training technique which involved no handling between trials. These authors were testing Zucker's (1965) hypothesis that handling represented a major component of the septal deficit, and his report that no deficit occurs on one-way tasks when handling is not used. In the current study, handling techniques were used, and a deficit was obtained with both groups of lesioned subjects. As the magnitude of effect was not the same in both groups, these results are consistent with the hypothesis that handling results in differential effects of septal lesions across strain or species.

These findings also support the hypothesis that brain lesions interact with preexisting genetic differences in rats. Although differences in control strains were statistically nonsignificant, Wistar albinos were consistently lower in emotionality than were the Long-Evans rats, an effect that was amplified by lesions of the septum. Furthermore, while septal lesions induced changes in all three types of avoidance responses, a Lesion by Strain interaction was apparent only for one-way avoidance. This effect probably reflects the fact that preexisting genetic differences may be task specific, as animals bred for high or low performance on a shuttle task do not differ on one-way avoidance (Satinder \& Petryshyn, 1974). However, unlike the genetic studies, this Strain by Lesion effect cannot be traced to a single underlying factor. Despite the finding that those animals in groups with high reactivity scores also had high one-way avoidance scores, the analysis of covariance indicates that variations in emotionality do not account for variations in avoidance learning. Thus, at present, the relation between septal damage and genetic heritage can only be interpreted as a complex, though unspecified, interaction. 


\section{REFERENCE NOTE}

1. Levinson, D. M., Reeves, D. L., \& Buchanan, D. R. Effects of septal lesions on aggression in the guinea pig. Paper presented at the 85th annual convention of the American Psychological Association, San Francisco, 1977.

\section{REFERENCES}

Bignami, G. Selection for high rates and low rates of avoidance conditioning in the rat. Animal Behaviour, 1965, 13, 221-227.

Brady, J. V., \& NaUta, W. J. H. Subcortical mechanisms in emotional behavior: Affective changes following septal forebrain lesions in the albino rat. Journal of Comparative and Physiological Psychology, 1953, 46, 339-346.

Buddington, R. W., King, F. A., \& Roberts, L. Emotionality and conditioned avoidance responding in the squirrel monkey following septal injury. Psychonomic Science, 1967, 8, 93-94.

DEAGLE, J. H., \& LUBAR, J. F. Effect of septal lesions in two strains of rats on one-way and shuttle avoidance acquisitions. Journal of Comparative and Physiological Psychology, 1971, 77, 277-281.

DEGRoo' $\mathrm{r}$, J. The rat forebrain in stereotaxic co-ordinates. Amsterdam: N.V. Noord-Hollandsche Uitgevers Maatschappij, 1959.

Freudenberger, C. B. A comparison of the Wister albino and the Long-Evans hybrid strain of the Norway rat. American Journal of Anatomy, 1932, 50, 293-349.

Hays, W. L. Statistics for the social sciences. New York: Holt, Rinehart and Winston, 1973.

KAADA, B., RASMUSSEN, E., \& KveIM, O. Impaired acquisition of passive avoidance behavior by subcallosal, septal, hypothalamic and insular lesions in rats. Journal of Comparative and Physiological Psychology, 1962, 55, 661-670.

KENYON, J., \& KREICKHAUS, E. E. Enhanced avoidance behavior following septal lesions in the rat as a function of lesion size and spontaneous activity. Journal of Comparative and Physiological Psychology, 1965, 59, 466-468.

KING, F. A. Effect of septal and amygdaloid lesions on emotional behavior and conditioned avoidance response in the rat. Journal of Comparative and Physiological Psychology, 1958, 126, 57-63.

MCCleARY, R. A. Response specificity in the behavioral effects of limbic system lesions. Journal of Comparative and Physiological Psychology, 1961, 54, 605-613.

MOORE, R. Y. Effects of some rhinencephalic lesions on retention of conditioned avoidance behavior in cats. Journal of Compar. ative and Physiological Psychology, 1964, 57, 65-71.

Nakamura, C. Y., \& Anderson, N. H. Avoidance behavior differences within and between strains of rats. Journal of Comparative and Physiological Psychology, 1962, 55, 740-747.

Oliverio, A. Genetic variations and heritability in a measure of avoidance learning in mice. Journal of Comparative and Physiological Psychology, 1971, 74, 390-397.

Oliverio, A., Castellano, C., \& Messeri, P. A. Genotypedependent effects of septal lesions on different types of learning in the mouse. Journal of Comparative and Physiological Psychology, 1973, 82, 240-246.

Satinder, K. P., \& Petryshyn, W. R. Interaction among genotype, unconditioned stimulus, d-amphetamine and one-way avoidance behavior of rats. Journal of Comparative and Physiological Psychology, 1974, 86, 1059-1973.

Sodetz, F. J., \& BunNell, B. N. Septal ablation and the social behavior of the golden hamster. Physiology \& Behavior, 1970, 5, 79-88.

STONE, C. P. Wildness and savageness in rats of different strains. In K. S. Lashley (Ed.), Studies in the dynamics of behavior. Chicago: University of Chicago Press, 1932.

Thomas, G. A., Hostetter, G., \& Barker, D. J. Behavioral functions of the limbic system. In E. Stellar \& J. M. Sprague (Eds.), Progress in physiological psychology (Vol. II). New York: Academic Press, 1968. Pp. 229-311.

Ursin, H., Linck, P., \& MCCleARY, R. A. Spatial differentiation of avoidance deficit following septal and cingulate lesions. Journal of Comparative and Physiological Psychology, 1969, 68, 74-79.

VANDERWOLF, C. H. Effect of combined medial thalamic and septal lesions on active-avoidance behavior. Journal of Comparative and Physiological Psychology, 1964, 58, 31-37.

Van Hoesen, G. W., McDougall, J. M., \& Mitchell, J. C. Anatomical specificity of septal projections in active and passive avoidance behavior in rats. Journal of Comparative and Physiological Psychology, 1969, 68, 80-89.

ZUCKER, I. Effect of lesions of the septal-limbic area on the behavior of cats. Journal of Comparative and Physiological Psychology, $1965,60,344-352$.

(Received for publication June 28, 1978; revision accepted August 15, 1978.) 